\title{
Mudança estrutural e crescimento econômico
}

\author{
Annalisa Primi, Mario Cimoli e Sebastián Vergara *
}

Gabriel Porcile $^{* *}$

\section{Introdução}

No seu livro clássico Schumpeter (1912) ressalta que o crescimento econômico se sustenta principalmente na mudança estrutural, na criação de novos bens, novos mercados e novos meios de transporte - que ele de forma genérica designava como a criação de novas funções de produção. Durante as décadas de sessenta e setenta, no entanto, a economia convencional deu muito pouca atenção à estrutura produtiva, com algumas valiosas exceções. Prevaleciam então os modelos agregados de crescimento exógeno, cujo foco era estimar o crescimento da produtividade total dos fatores com base na contabilidade do crescimento.

Todavia, importantes contribuições nas linhas evolucionista (Nelson e Winter, 1982) e keyensiana (Thirlwall, 1979) ocorreram nesses anos, resgatando a importância da mudança qualitativa e da estrutura produtiva no crescimento. No modelo de Nelson e Winter, os distintos setores variam em termos de sua capacidade de gerar ganhos de produtividade e, portanto, de estimular o crescimento. A oportunidade tecnológica, definida em termos do salto de produtividade ou de qualidade que é possível obter a partir do investimento em P\&D, é específica ao setor.

Nos modelos keynesianos com restrição de balanço de pagamentos a taxa de crescimento da demanda mundial é diferente entre setores, e a capacidade de uma economia de crescer no longo prazo depende de sua capacidade de ingressar nos mercados com mais alta elasticidade renda da demanda. Aqui também a estrutura produtiva é importante, embora o foco neste caso seja mais restrito, a especialização internacional.

Outros autores têm realizado importantes contribuições a esta perspectiva, mas escapa aos objetivos deste trabalho apresentar uma discussão mais ampla do debate. Todavia, tentarse-á mostrar algumas evidências que sugerem que existe uma forte relação entre crescimento, mudança estrutural e especialização, como sugerido pelas escolas evolucionista e keynesiana (ver Cimoli et al, 2005).

\footnotetext{
* División de Desarrollo Productivo y Empresarial, CEPAL-Santiago.

** Departamento de Economía, UFPR.
} 


\section{Setores difusores de tecnologia}

Um primeiro exercício é observar a mudança no peso dos chamados setores difusores de tecnologia na estrutura industrial de um país (mudança estrutural) e ver se essa mudança guarda relação com suas taxas de crescimento. Os setores difusores de tecnologia são os setores 381-385 da Classificação Industrial Internacional (SITC) e incluem os setores da metal-mecânica e da eletrônica, relativamente mais intensivos em tecnologia que o resto da indústria. Eles seriam capazes de gerar externalidades tecnológicas para o conjunto da indústria. Haveria a partir desses setores efeitos dinâmicos de aprendizado e de arraste, capazes de favorecer taxas mais altas de crescimento macroeconômico.

\section{Gráfico 1. Relação entre participação dos setores difusores de tecnologia na estrutura industrial e taxa de crescimento econômico}

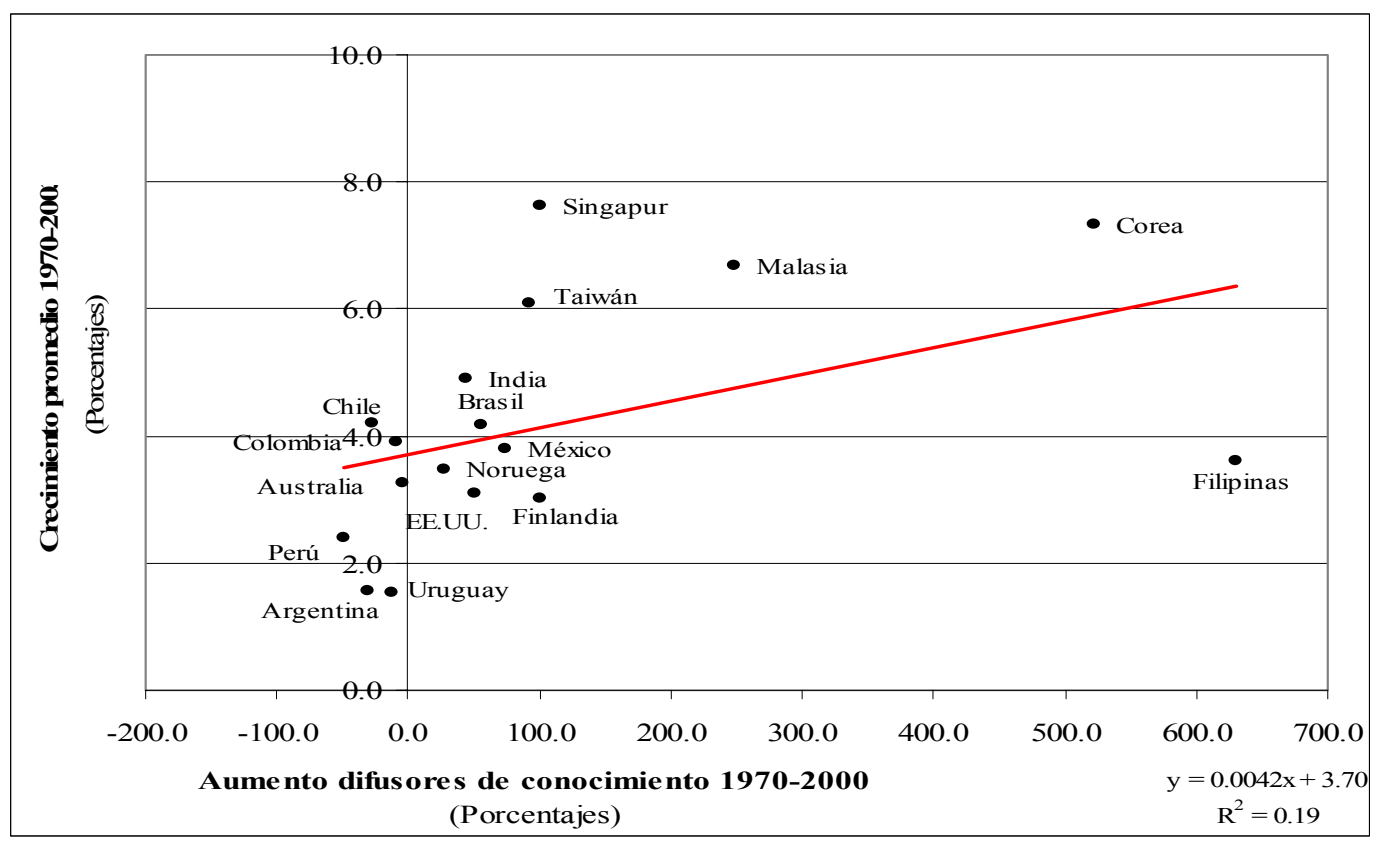

Fonte: elaboração dos autores.

O gráfico 1 mostra a relação entre o aumento dos setores difusores de conhecimentos e o crescimento econômico numa amostra de 17 países. É aparente que exista entre essas duas variáveis uma relação positiva. Destaca-se em particular o aumento do peso dos setores difusores de conhecimentos nas economias asiáticas, e a fraca mudança estrutural no caso das economias latino-americanas.

O que acontece quando a mudança estrutural é observada desde a perspectiva da especialização internacional? 
Gráfico 2. Relação entre participação dos setores difusores de tecnologia na estrutura industrial e a taxa de adaptabilidade no comércio internacional

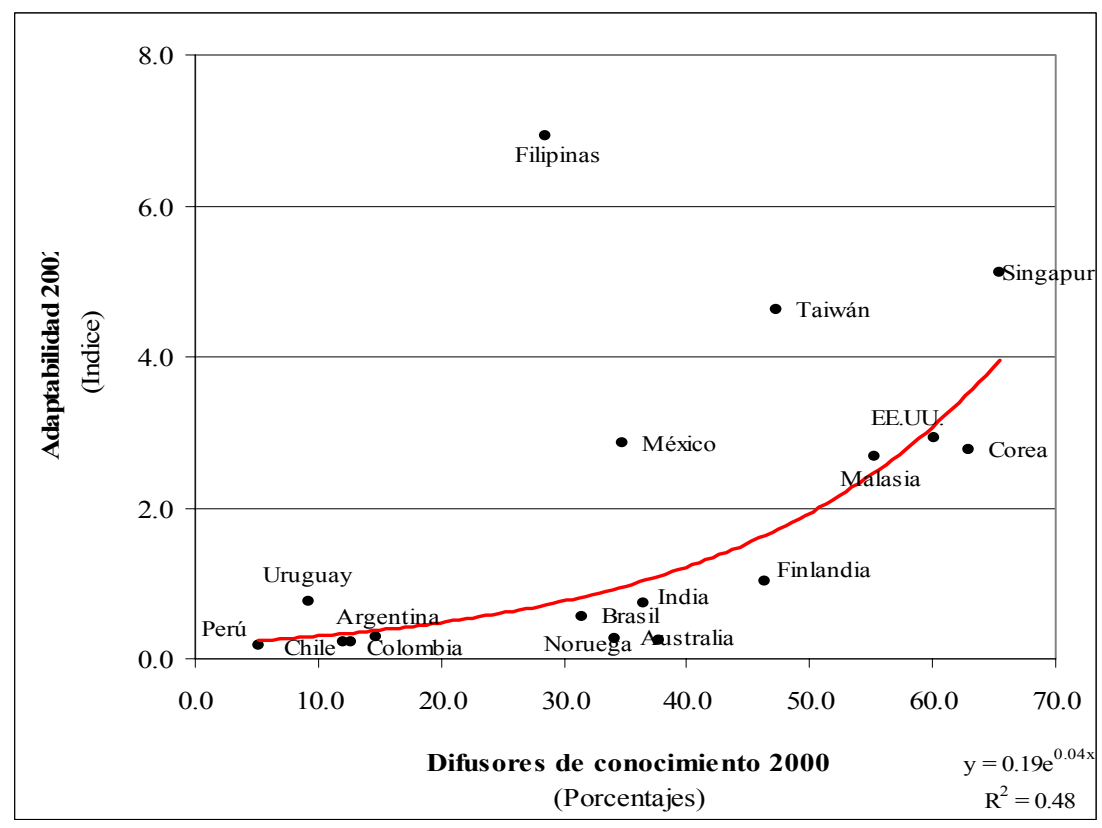

Fonte: elaboração dos autores.

O gráfico 2 mostra que há uma associação positiva entre o peso dos setores difusores de conhecimentos e o chamado índice de adaptabilidade no comércio internacional. Este índice é definido pelo quociente entre a participação dos setores dinâmicos sobre a participação dos setores estagnados nas exportações totais. Naturalmente, um valor mais elevado desse índice reflete uma maior elasticidade renda das exportações. Assim, o gráfico 2 oferece evidência favorável também para o papel da mudança estrutural no sentido do modelo keynesiano - a mudança estrutural permite que o país se beneficie da demanda internacional via uma maior elasticidade renda das exportações. 


\section{Tecnologia e mudança estrutural}

Como se relaciona a mudança estrutural com o esforço tecnológico de cada país? O gráfico 3 ajuda a ilustrar esse ponto.

Gráfico 3. Relação entre participação dos setores difusores de tecnologia na estrutura industrial e o investimento em I+D

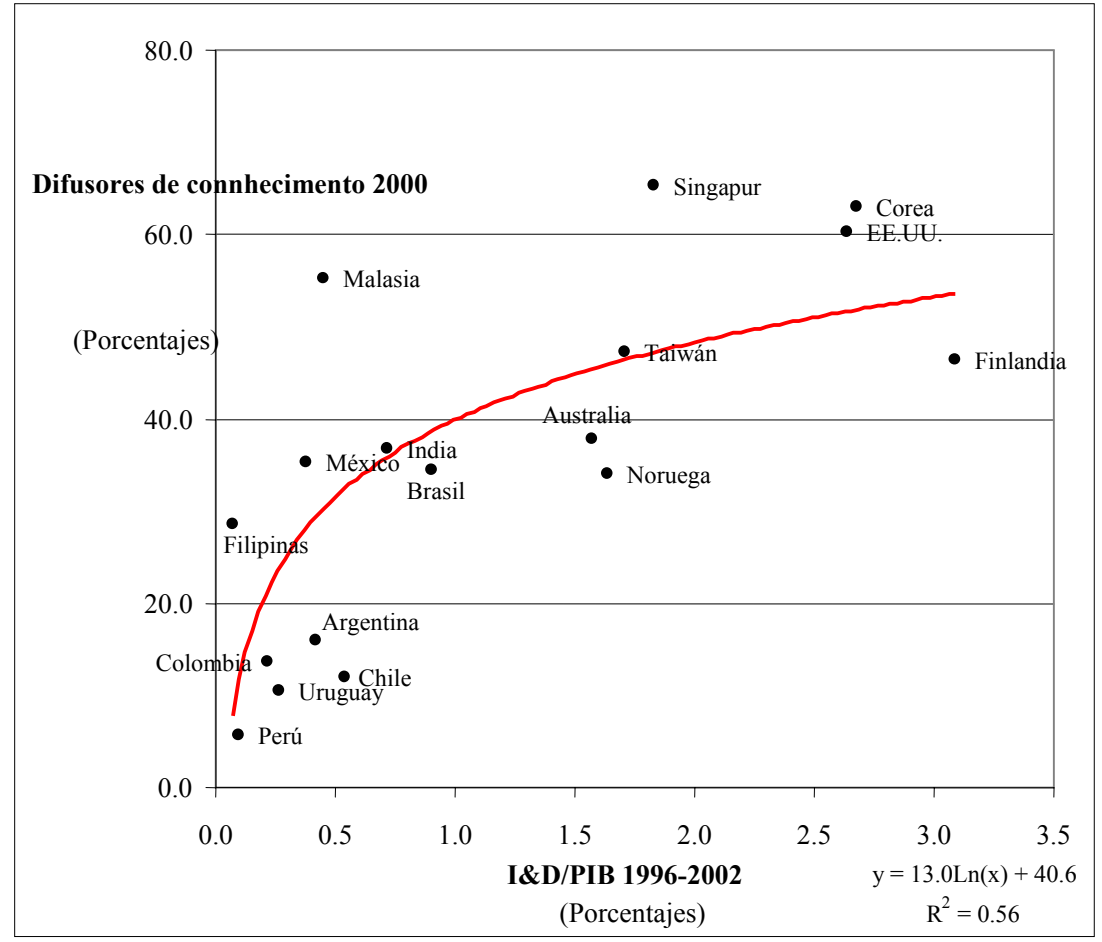

Fonte: elaboração dos autores.

O gráfico 3 mostra que aqueles países em que os setores difusores de tecnologia têm um peso maior na estrutura industrial são também países em que se investe mais em I+D. Há sem dúvida uma relação de causalidade nos dois sentidos: o peso dos setores difusores de conhecimentos estimula novos investimentos em tecnologia, e ao mesmo tempo esses investimentos fortalecem o peso daqueles setores.

\section{Comentários Finais}

A mudança estrutural (o aumento do peso dos setores difusores de conhecimentos no valor adicionado industrial) associa-se positivamente com uma especialização internacional mais dinâmica, com maiores investimentos em tecnologia e com maiores taxas de crescimento econômico. Demanda e oferta relacionam-se por meio da capacidade da economia de reagir e se adaptar frente às mudanças nos mercados externos. No longo prazo, Keynes e Schumpeter andam juntos. 


\section{Referências Bibliografias}

Cimoli, M. Porcile, G. Primi, A, y Vergara, S "Cambio Estructural, Heterogeneidad Productiva y Tecnología en América Latina”, en Mario Cimoli (ed) Heterogenedidad Estructural, Asimetrias Tecnologicas y Crecimiento en América Latina. BID-CEPAL, 2005.

McCombie, JSL e Thirlwall, A. Economic Growth and the Balnce-of-Payments Constraint. St Martin's Pess, 1994.

Nelson, R. e Winter, R. An Evolutionary Theory of Economic Change. Harvad University Press, 1982.

Schumpeter, JA Theory of Economic Development. Leipzig: Duncker and Humblo. 
